\title{
Turning the Ship: The Transformation of DESY, 1993-2009
}

\author{
Thomas Heinze*, Olof Hallonstenf ${ }^{\dagger}$, and Steffi Heinecke ${ }^{\ddagger}$
}

This article chronicles the most recent history of the Deutsches Elektronen-Synchrotron (DESY) located in Hamburg, Germany, with particular emphasis on how this national laboratory founded for accelerator-based particle physics shifted its research program toward multi-disciplinary photon science. Synchrotron radiation became DESY's central experimental research program through a series of changes in its organizational, scientific, and infrastructural setup and the science policy context. Furthermore, the turn toward photon science is part of a broader transformation in the late twentieth century in which nuclear and particle physics, once the dominating fields in national and international science budgets, gave way to increasing investment in the materials sciences and life sciences. Synchrotron radiation research took a lead position on the experimental side of these growing fields and became a new form of big science, generously funded by governments and with user communities expanding across both academia and industry.

Key words: synchrotron radiation; photon science; particle accelerators; transformation; DESY.

\section{Introduction}

The Deutsches Elektronen-Synchrotron (DESY) is a German national laboratory for photon science and particle and accelerator physics located in Hamburg, with an outstation in Zeuthen near Berlin. This article recounts DESY's recent history, with particular emphasis on how a laboratory once founded for accelerator-based high energy physics shifted its research program to multi-disciplinary "photon science," a collective name for the use of synchrotron radiation and free-electron laser for the study of materials, including biomaterials. Initially regarded by high energy physicists as an unwanted byproduct of accelerators built for exploring subatomic particles, synchrotron radiation was used in so-called parasitic mode at

\footnotetext{
* Thomas Heinze is Professor of Organizational Sociology and Deputy Director of the Interdisciplinary Center for Science and Technology Studies (IZWT) at the University of Wuppertal, Germany.

${ }^{\dagger}$ Olof Hallonsten is a Senior Researcher at Lund University and was Humboldt Fellow at the University of Wuppertal in 2014.

* Steffi Heinecke is a Postdoctoral Researcher at the Institute of Sociology, University of Wuppertal.
} 
several accelerators worldwide, but grew to become a big science in its own right, with large numbers of dedicated accelerator laboratories. ${ }^{1}$ Today, DESY operates two photon science machines (FLASH and PETRA III), but no longer a high energy physics machine. A next generation photon science machine, the European XFEL officially opened in September 2017.

Synchrotron radiation is electromagnetic radiation in the wavelength spectrum from infrared, over visible and ultraviolet light, to X-rays down to wavelengths of 0.1 Ångström (or $0.01 \mathrm{~nm}$ ). Though initially explored parasitically at high energy physics labs, synchrotron radiation is currently produced by purpose-built storage rings. Often called third-generation light sources, the rings keep particles stored in circulation, producing continuous beams of synchrotron radiation. Different experimental applications require different wavelengths (or photon energies), and sometimes very specific wavelengths (that is, monochromatic beams). The use of linear accelerators to produce so-called free-electron laser is a complementary activity that many synchrotron radiation laboratories have engaged in since the 1990s. Free-electron lasers produce radiation with dramatically enhanced performance parameters (coherence, brilliance, length of pulses). Free-electron lasers are sometimes called "fourth generation" light sources and are not regarded as replacements for synchrotron radiation sources, but complementary facilities that open up new areas of discovery. ${ }^{2}$

Synchrotron radiation research began at DESY in the early 1960s with a grant from the German Research Foundation (DFG) to build an "observation bunker" in order to exploit the scientific potential that synchrotron radiation offered for ultraviolet spectroscopy. ${ }^{3}$ The bunker hosted the final part of a thirty-meter beamline from the synchrotron to an experimental station. In the late 1960s, an increasing number of research groups from various German universities, mostly in solid state physics, but also chemistry and materials science, started to conduct experiments in collaboration with synchrotron radiation scientists at DESY. In the early 1970s, the European Molecular Biology Laboratory (EMBL) established an outstation at DESY, adding credibility to the synchrotron radiation activities on site.

When DESY's second machine, the double storage ring DORIS, became operational in the early 1970s, the Federal Research Ministry (BMFT; BMBF since 1995) agreed to become the chief sponsor for university groups that wanted to use synchrotron radiation at DESY. However, severe initial beam instabilities prevented DORIS from reaching the expected brilliance and the decision of particle physicists to study collisions at significantly lower energy levels following the discovery of the J/psi particle by Burton Richter and Samuel Ting in the mid1970s made synchrotron radiation experiments in the much-desired X-ray spectral range practically impossible. The situation improved when DORIS was converted to a single-ring operation and when a separate injector device was built for DESY's new flagship machine, the positron electron ring accelerator PETRA, freeing DORIS from its function as an injector (that is, a separate accelerator that 
feeds larger ones with accelerated particles) and thus removing one major obstacle on the long way to a dedicated synchrotron radiation facility.

Synchrotron radiation became increasingly useful for various scientific fields, including chemistry, materials science, and structural biology, when continuous technological advances, most importantly the storage ring (such as DORIS), allowed a continuous and stable beam of radiation to be extracted instead of the flickering light of previous synchrotrons (for example, the first synchrotron machine at DESY, which lent its name to the laboratory). Other significant developments included arrays of magnets (insertion devices) that increased the intensity and eventually made the production of hard X-rays possible, helping achieve highly brilliant, almost monochromatic photon beams. ${ }^{4}$

The parasitic mode of synchrotron radiation research at DESY reached its limits in the late 1970s, when more and more users applied for beam time at DORIS and their scientific results were recognized as novel and highly important. ${ }^{5}$ By the end of the 1970s, a laboratory, HASYLAB, was founded to coordinate all synchrotron radiation activities at DESY. However, the BMFT did not provide the funding necessary to hire enough scientific and technical staff for HASYLAB. Therefore, the leadership at DESY had to fund synchrotron radiation staff from its particle physics budget, a situation that caused considerable strain, particularly between the DESY leadership and BMFT. It was not until the late 1980s that the BMFT finally provided the funding it had promised. Over time, it became clear that HASYLAB's facilities and staff needed to be developed further to seek and maintain a leading global position (Table 1).

Research with synchrotron radiation was recognized as a formal organizational goal of DESY's operations in the early 1990s and DORIS was converted into a third-generation light source fully dedicated to synchrotron radiation research. In addition, leading scientists from both the high energy physics program and synchrotron radiation program forged a coalition that eventually culminated in both the conversion of PETRA into a third-generation light source (PETRA III) and the building of the European X-ray Free Electron Laser (XFEL). Here, we chronicle the final seventeen years of DESY's transformation, from 1993 to 2009, building on two previous articles featuring the development of synchrotron radiation research at DESY from 1962 to 1993 and additional literature on the history of DESY. ${ }^{6}$ The historical account closes with the recruitment of the first photon scientist as chairman of DESY's Board of Directors, which coincided with the laboratory's fiftieth anniversary. This milestone is interpreted as a marker of the completion of the transformation of DESY from a high energy physics laboratory into a photon science laboratory.

Synchrotron radiation research grew in parallel with decreasing usefulness of existing accelerator facilities for experimental high energy physics at the energy frontier and a strong dependence on the construction of ever larger, and thus more expensive accelerators with higher energies. This also meant that national research programs were increasingly substituted by international efforts. Indicative of this 
Table 1. Synchrotron Radiation Research at HASYLAB

\begin{tabular}{lllll}
\hline Year & $\begin{array}{l}\text { Number of } \\
\text { external users }\end{array}$ & $\begin{array}{l}\text { Number of } \\
\text { external institutes }\end{array}$ & $\begin{array}{l}\text { Number of } \\
\text { experimental } \\
\text { stations }\end{array}$ & $\begin{array}{l}\text { Annual beam hours for } \\
\text { synchrotron radiation }\end{array}$ \\
\hline 1992 & 718 & 146 & 31 & 2,356 \\
1993 & 833 & 180 & 31 & 1,202 \\
1994 & 996 & 216 & 42 & 3,124 \\
1995 & 1,111 & 246 & 42 & 4,023 \\
1996 & 1,220 & 247 & 42 & 4,226 \\
1997 & 1,290 & 225 & 42 & 4,595 \\
1998 & 1,500 & 228 & 41 & 4,690 \\
1999 & 1,600 & 261 & 42 & 5,497 \\
2000 & 1,450 & 230 & 42 & 5,010 \\
2001 & 1,662 & 247 & 42 & 5,348 \\
2002 & 1,550 & 239 & 41 & 5,757 \\
2003 & 1,479 & 271 & 40 & 4,763 \\
2004 & 1,415 & 250 & 38 & 4,781 \\
2005 & 1,560 & 360 & 43 & 5,045 \\
2007 & 1,700 & 358 & 41 & 5,660 \\
\hline
\end{tabular}

development is the Large Hadron Collider (LHC) in Geneva, which remains the main operating accelerator facility for high energy physics at the energy frontier in the world, whereas former strongholds of the field, including the United States, Germany, the United Kingdom, and Russia, have cut their national acceleratorbased high energy physics programs. ${ }^{7}$ Many of these accelerator facilities were converted and redeployed for synchrotron radiation, with accelerator designers and constructors redirected to the development of synchrotron radiation sources, spallation neutron sources, and free-electron lasers. ${ }^{8}$

In analyzing the increasing importance of research with synchrotron radiation as a gradually growing experimental activity at DESY, this article not only contributes to understanding the laboratory's internal changes and their causes and consequences, but also details an important piece of the history of science and technology in the late twentieth century that is relevant for similar developments in other national contexts, such as the conversion of particle accelerators and the redirection of physical and intellectual resources from nuclear and particle physics to materials science at various laboratories around the globe. ${ }^{9}$ Therefore, we examine DESY's transformation using theoretical categories from the historical institutionalism literature, including four general modes of change at large laboratories that invite comparisons with other laboratories and facilities, and that can be observed at the level of laboratory 
infrastructure, research fields within the laboratory, and formal organizational structure: layering, conversion, displacement, and dismantling. A key insight from the historical institutionalism literature is that institutional change oftentimes is neither disruptive nor revolutionary, but proceedes in steps and gradually-nevertheless, the accumulated results of such gradual change can transform existing structures fundamentally. ${ }^{10}$

Layering means new entities and resources for photon science are added to the laboratory, enabling accommodation of the new research field without directly challenging existing structures, such as when photon science resources were added to DESY's existing high energy physics capabilities. Conversion refers to when the research capacity for one set of goals is redirected to other ends, such as when large technical infrastructure for particle physics (PETRA) was redeployed for photon science (PETRA III). Displacement means that existing research capacity is discontinued, such as when scientific experiments in high energy physics were discontinued at DESY and new experiments for photon science were set up in their place. Finally, dismantling means that the existing research capacity is discontinued without anything added in its place, such as when technical infrastructure or organizational units in high-energy physics cease to be used without being replaced (HERA).

Layering, conversion, displacement, and dismantling unfold at multiple temporal and spatial scales and mutually influence one another. For example, the layering of a new photon science machine to the laboratory's existing high energy physics accelerator infrastructure may result in a new scientific activity (science layering) on the new machine. In addition, the new infrastructure may lead to the establishment of a new organizational unit (organizational layering). The components of the existing particle physics infrastructure itself may simultaneously be restructured (infrastructure conversion) at various points in time and as part of the overall process of laboratory transformation in which photon science becomes the predominant research program (science displacement). Thus, using the theoretical categories of historical institutionalism helps us understand micro-level events in one laboratory as elements in transformation processes that constitute the building blocks of broader developments; here, this is the shift toward using former particle physics facilities for photon science research.

This article describes the most recent years in DESY's gradual transformation, relying on four types of sources: first, archival material obtained at DESY in Hamburg, including the minutes of DESY's Administrative Council (Verwaltungsrat), Board of Directors (Direktorium), Scientific Council (Wissenschaftlicher Rat), Extended Scientific Council (Erweiterter Wissenschaftlicher Rat), annual reports (Jahresberichte), annual scientific reports (Wissenschaftliche Jahresberichte), and fiscal plans (Wirtschaftspläne); second, archival material concerning DESY obtained from other archives, including the SLAC National Accelerator Laboratory in Menlo Park, California, the German Parliament (Bundestag), and the German Science Council (Wissenschaftsrat); 
third, personal interviews with key contemporary witnesses; and fourth, secondary literature, including literature on DESY and big science facilities in Germany and the United States. ${ }^{11}$

\section{German Science Policy in the 1990s and 2000s}

DESY was founded in 1959 during the heyday of nuclear and particle physics, at a time when governmental science budgets, including those for high energy accelerator facilities, seemed almost inexhaustible. ${ }^{12}$ This contrasts with the budgetary constraints on public investments in science and technology that prevailed in Germany in the 1990s. The country's reunification incurred considerable expenses for both the federal and state governments. At the same time, the economy slipped into a severe recession. Many areas of public life had to accept tighter budgets, including science and technology. Thus, the 1990s were a period of stagnation in the government budget for science: $€ 20.0$ billion in 1991 compared to $€ 20.2$ billion in 2000 (in 2010 prices). ${ }^{13}$

In the 2000s, although with a stronger economy and after large monetary transfers had already been made to the former East Germany, both the federal and state governments did not spent substantially more money on science and technology, increasing their budget merely by three percent, from $€ 20.1$ billion in 2001 to $€ 20.7$ billion in 2010 . $^{14}$ This small growth pales in comparison to the considerable budget growth in research and development in other developed countries. For example, in the United States, the federal science budget grew approximately forty percent in the same time period, from $\$ 91.8$ billion in 2001 to

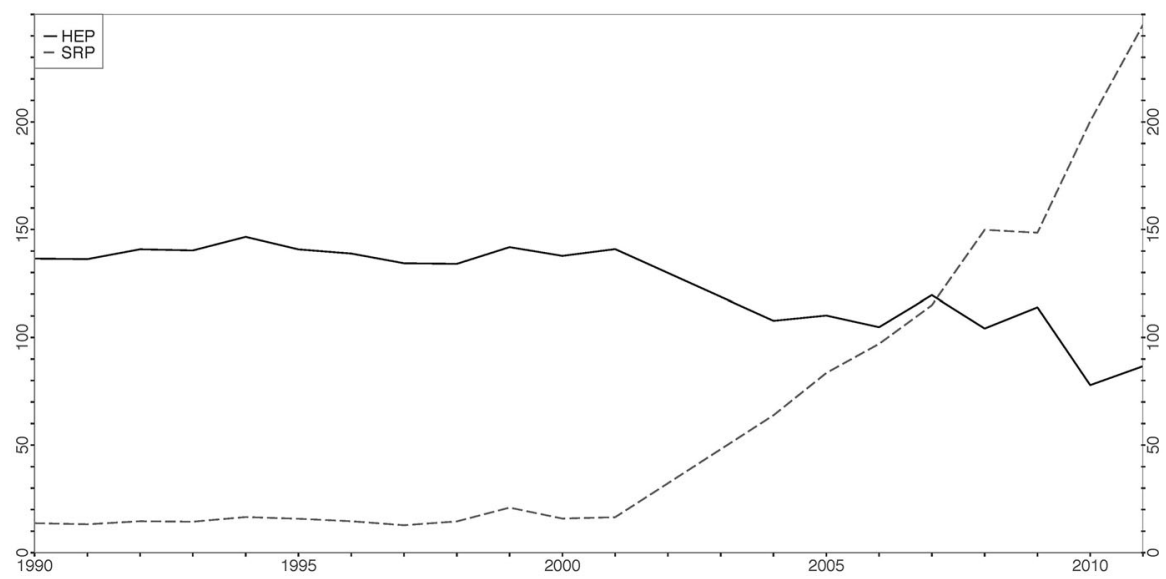

Fig. 1. High energy physics and photon science budgets at DESY, 1990-2011. Source: DESY, ed., Wirtschaftspläne 1992-2014; additional data from EMBL and MPG. Figure presents millions of Euro in 2005 prices 
$\$ 128.9$ billion in $2010 .{ }^{15}$ Growth rates for the National Science Foundation and the Department of Energy's Basic Energy Sciences programs were very similar. ${ }^{16}$

DESY's funding matches the overall budget trend, but the German federal government's growing commitment to funding photon science in the 2000s is clearly visible. The overall stagnation in the federal science budgets of the 1990s can be seen in figure 1, with the annual high energy physics and photon science budgets stable at approximately $€ 140$ million (in 2005 prices). Beginning in the early 2000s, depite the small growth in the federal science spending, DESY's photon science budget started to expand considerably, whereas the funding for high energy physics gradually dwindled. At the same time, however, the German government contributed substantial funds for the construction of the LHC in Geneva: in the first five years of the millennium, as much as half of the total annual CERN budget of roughly €700-900 million went directly to LHC construction, with Germany's share stable at roughly one fifth, or between $€ 150$ million and $€ 180$ million. $^{17}$

The second development in German science policy of the 1990s and 2000s was the widely debated problem that government-funded research organizations and public universities were increasingly insulated from one another, with low degrees of mutual collaboration. This situation was perceived by the BMBF as stifling to the overall progress of science and technology. ${ }^{18}$ In 1996, the federal government and state governments decided to conduct "system evaluations" for the Max Planck Society (sixty institutes), Fraunhofer Society (forty institutes), Leibniz Association (eighty-two institutes and service centers), Helmholtz Association (sixteen research centers), and DFG. ${ }^{19}$ DESY belonged to the Helmholtz Association, which had been formed as an umbrella organization for the German "big science centers" ("Großforschungseinrichtungen") just a year earlier. ${ }^{20}$ In 1998 and 1999, two expert committees were set up to evaluate the Fraunhofer Society and Max Planck Society (and DFG), including their relationships with the universities. ${ }^{21}$ Upon request from the federal government, the Science Council conducted such evaluations for the Leibniz Association (2000) and Helmholtz Association (2001), again with a focus on the relationships of their institutes and centers with the universities. ${ }^{22}$

Regarding the research centers of the Helmholtz Association, the Science Council recommended increasing their efforts to recruit leading scientists together with their neighboring universities. These joint professorial appointments would allow "mutual sharing of information and coordination" and the building of "clusters in strategically important research fields." Furthermore, Helmholtz research centers were asked to consider the possibility of establishing joint institutes with the universities. ${ }^{23}$ As shown below, DESY leadership acted in line with these recommendations by establishing the Center for Free Electron Laser Science (CFEL) in 2007, a joint facility between the Helmholtz Association, Hamburg University, and the Max Planck Society. The CFEL not only received new research and administration buildings, but was also endowed with five new professorial staff positions for joint appointments with Hamburg University. 
A third development in German science policy occurred as a direct consequence of the system evaluations. Based on the recommendations resulting from the evaluations, the federal government requested the Max Planck Society, Fraunhofer Society, Leibniz Association, and Helmholtz Association carry out internal reforms. ${ }^{24}$ The most sweeping reforms occurred at Helmholtz, based on the Science Council's recommendation to establish a new funding structure along with broadly defined research programs and a suitable governance structure for its planning and administration. ${ }^{25}$

In contrast to established practice in which Helmholtz centers were directly and individually funded $(90 \%$ by the federal government, $10 \%$ by the governments of the states in which the research centers were located; the City of Hamburg in the case of DESY), the new budget structure implied that all laboratories would compete for shares in these research programs and the allocation of funding would be founded on peer review-based evaluations of five-year research plans. In addition, the Science Council recommended establishing a new umbrella organization whose president and senate would be key actors in both research strategy planning and the allocation of funds. ${ }^{26}$

The eagerness and speed with which the BMBF pushed forward and implemented the Council's recommendations spurred criticism from members of the Bundestag, particularly the opposition parties, who feared that the Helmholtz reforms would result in "oversteering," "increased bureaucratization," troduction of command science," and the "disempowerment of research centers." 28 Early empirical studies partly support these allegations, particularly the trend toward increased oversteering and bureaucratization, ${ }^{29}$ but a comprehensive evaluation of the Helmholtz reforms has not yet been conducted.

The new funding and governance structures, which were eventually implemented by the end of 2001, also implied-in principle-less involvement of the federal government in setting the research agendas of Helmholtz centers. In fact, as shown below, the CFEL (initiated by DESY) was founded based on decisions by the senate of the remodeled Helmholtz Association and thus as part of the broadly defined research programs to which all national laboratories contributed. Yet, the BMBF reserved its right to intervene in Helmholtz's research agendas when deemed necessary. Regarding DESY, this happened in the mid-2000s when, despite the Science Council's recommendation to fund both the International Linear Collider (TESLAILC), a high priority machine for particle physics, and one large photon science machine, the European XFEL, the BMBF did not provide any funding for the former, but did provide substantial funding for the latter. Unsurprisingly, this caused considerable frustration among particle physicists at DESY and elsewhere.

In summary, the following contextual factors in German science policy in the 1990s and 2000s shaped DESY's turn towards photon science. First, after a decade of stagnation in science budgets, funding for high-energy physics started to decline as the funding for photon science increased considerably. Second, the Helmholtz Association, the umbrella organization for all national laboratories, including 
DESY, was subject to sweeping administrative reforms, most importantly regarding the streamlining of the centers' research agendas along broadly defined programs. Third, the BMBF, despite a supportive evaluation from the Science Council, did not fund yet another accelerator for experimental particle physics at DESY, instead providing substantial funding for a major new photon science machine.

\section{The Vacuum Ultraviolet Free Electron Laser (VUV-FEL)}

Our analysis begins in 1993, when HASYLAB was reasonably well-equipped with support staff, DORIS had been transformed successfully into a fully dedicated synchrotron light source (DORIS III), and the synchrotron radiation program had been integrated in DESY's statutes. In the same year, Jochen Schneider followed Gerhard Materlik (both photon scientists) as HASYLAB director, and Björn Wiik (high energy physicist) became chairman of DESY's Board of Directors. Both Schneider and Materlik became leading figures in the transformation of DESY into a dedicated photon science laboratory. Together with Wiik, they forged a coalition between the high energy and accelerator physicists on the one hand, and photon scientists on the other hand. This coalition eventually led to the building of the first free-electron laser in the vacuum ultraviolet energy region (VUV-FEL) as part of the TESLA Test Facility (TTF), the conversion of PETRA into a thirdgeneration synchrotron light source (PETRA III), and the BMBF's commitment to fund fifty percent of the costs of the European XFEL.

When Wiik became chairman of the Board of Directors in 1993, he had already been at the laboratory for more than twenty years. Wiik had a strong interest in electron-proton collisions and succeeded, together with his predecessor Volker Soergel, to build HERA, a large $300 \mathrm{GeV}$ electron-proton collider with a $6.3 \mathrm{~km}$ circumference. ${ }^{30}$ Many observers regarded HERA as too big and too expensive a project to ever be realized. Its sheer physical size and considerable technical and administrative complexity required great leadership qualities. In this regard, Wiik played a key role in organizing political support for the funding and motivated and inspired scientists and technicians at DESY and from abroad to join the project. ${ }^{31}$ This leadership was also required in the laboratory's next big undertaking, the TeV Superconducting Linear Accelerator (TESLA).

First proposed in 1991, TESLA was meant to continue the accelerator-based particle physics program at DESY. ${ }^{32}$ Based on two beams (positrons colliding with electrons) coming from two opposite linear accelerators and built with superconducting resonators, this project presented a double technical challenge for DESY. First, the laboratory had never built a large linear accelerator. Compared to its North American sibling SLAC, DESY's technical expertise was firmly anchored in storage-ring technology, not linear accelerators. Second, the use of the superconducting radio frequency (SRF) technology for accelerators was novel and intrinsically risky because such a technical design had never been built and tested 
elsewhere. ${ }^{33}$ In response to this challenge, in 1992, DESY organized an international consortium of nineteen institutions from eight countries and established the TTF, where major components of the new accelerator were built and tested. ${ }^{34}$

However, in the early 1990s, there was little political support for funding a new particle physics machine at the BMFT. In 1993, during his inaugural visit to the BMFT as chairman of DESY's Board of Directors, Wiik presented the technological program that would be needed for realizing TESLA, but he received clear signals from Minister Heinz Riesenhuber that the BMFT was more interested in the development of key technologies (including materials science and the life sciences) than in building another single-purpose high energy physics machine. ${ }^{35}$ Therefore, Wiik and his colleagues modified the original TESLA concept and included a free-electron laser in its design. ${ }^{36}$

The close relationships between physicists at DESY and SLAC made the free-electron laser an opportune design choice. In February 1992, the concept of a free-electron laser was discussed during a workshop at SLAC on "Fourth Generation Light Sources." 37 It was at this workshop that Claudio Pellegrini (University of California at Los Angeles) proposed to rebuild the SLAC linear accelerator to an X-ray free-electron laser. ${ }^{38}$ Following the discussions at this workshop, a study group was formed at SLAC, which, in June 1992, submitted a project proposal to the Department of Energy, requesting $\$ 100,000$ in research and development funds for the project that had been given the name Linac Coherent Light Source (LCLS). ${ }^{39}$ In November 1992, Wiik was involved in the technical review committee that supported the proposal to conduct preliminary research for the project. ${ }^{40}$ In 1994, former HASYLAB's director Gerhard Materlik was co-organizer of the "Workshop on Scientific Applications of Coherent X-Rays" at SLAC with John Arthur and Herman Winick. ${ }^{41}$ After returning from his sabbatical at SSRL (1993-1994), Materlik convinced Wiik to include an X-ray laser in the superconducting linear accelerator project at DESY. ${ }^{42}$

This new X-ray laser was meant to substantially improve the technical and scientific aspects of synchrotron radiation research, essentially by enabling the production of coherent (laser) X-ray radiation. Compared to the state-of-the-art synchrotron sources at the time, such as the European Synchrotron Research Facility (ESRF), which opened in 1994 in Grenoble, the new X-ray laser would increase the beam intensity by several orders of magnitude and enable timeresolved studies at the femtosecond level, which was previously unachieved and opened up many new potential applications. ${ }^{43}$

However, synchrotron radiation researchers were generally skeptical about the technical and scientific feasibility of the X-ray free-electron laser: "The main concern was that the very high X-ray intensity would blow-up any sample on the beam path, making it impossible to obtain useful data." ${ }^{44}$ In 1996, at a workshop on fourth-generation light sources at the ESRF in Grenoble, several prominent French X-ray scientists said the LCLS would never work. ${ }^{45}$ In addition, potential 
users, including those in the life sciences, had "no interest in an expensive X-ray laser," ${ }^{46}$ not least of all because they "were perfectly happy with synchrotron radiation. ${ }^{47}$

Given the technical question of whether the self-amplified spontaneous emission (SASE) principle-the central technical concept of a free-electron lasercould be scaled to higher photon energies (X-rays) and in order to overcome the reservations of the synchrotron radiation community, the free-electron laser had to be successful at a lower energy (ultraviolet region). At DESY, a roadmap was established to test the feasibility of the free-electron laser in the vacuum ultraviolet energy region (VUV-FEL) first, and then build a VUV-FEL facility and a free-electron laser in the X-ray region. ${ }^{48}$ In 1995, a conceptual design was released for the VUV-FEL and both DESY's Scientific Council and Administrative Council approved the project that same year. ${ }^{49}$ Several years of construction and technical development followed. ${ }^{50}$ In 1999, the facility achieved initial operation. ${ }^{51}$ In February 2000, the laser beams achieved an intensity that proved the VUVFEL concept worked. ${ }^{52}$ In 2001, the VUV-FEL started operations for scientific experiments and was later renamed FLASH (figure 2). ${ }^{53}$

In parallel with the construction of the VUV-FEL, two developments provided momentum for building free-electron lasers in general. First, since the late 1990s, more and more experimental results proved that the free-electron laser was going to work. In particular, several research groups reported SASE measurements that were regarded as proof of principle. ${ }^{54}$ Second, in the United States, the Department of Energy took several steps toward building a free-electron laser in the hard X-ray energy region at SLAC. In January 1999, a review panel from the Basic Energy Sciences Advisory Committee concluded that the Department of Energy "should pursue the development of coherent light source technology in the hard $\mathrm{X}$-ray region as a priority. ${ }^{55}$ Based on that recommendation, the Department of Energy provided additional funding. Following the submission of the LCLS Design Report in January $2002,{ }^{56}$ they decided to go ahead with the more concrete planning. ${ }^{57}$ As the VUV-FEL had started operating successfully at DESY, the Department of Energy no longer wanted to build a test facility for a hard X-ray free-electron laser as SLAC had suggested, but rather a full-fledged user facility. ${ }^{58}$

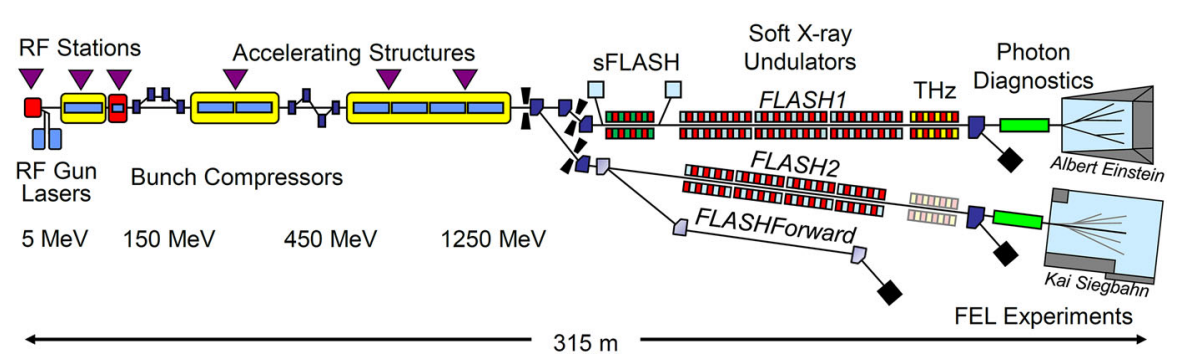

Fig. 2. Schematic layout of FLASH. Source: https://flash.desy.de/ (accessed March 20, 2017) 
At DESY, the integration of the FEL into the TESLA project proposal effectively connected the particle physics program and photon science program. ${ }^{59}$ Therefore, Wiik presented the linear collider as an "ideal driver for a free-electron laser" and a prerequisite for assuring "the highest standard regarding beam quality." ${ }^{60} \mathrm{He}$ advertised the linear collider, now in combination with the freeelectron laser, as DESY's future machine in many lectures and presentations. ${ }^{61}$ Thus, since the mid-1990s, and for the first time in its history, synchrotron radiation/photon science occupied a prominent place in DESY's research strategy.

The new partnership between particle and accelerator physicists and photon scientists developed in a similar way at SLAC. In one of its planning documents in the late 1990s, the SLAC leadership argued: "While seemingly quite different, the synchrotron radiation and particle physics programs are in fact allied programs that benefit one another, mutually driving back the frontiers of accelerator technology that both depend on for research." 62 When the planning for the LCLS became more concrete in the early 2000s, accelerator-based particle physics and photon science were portrayed as close allies. ${ }^{63}$

Following the increase in strategic importance, the DESY Administrative Council, in consultation with Wiik, strengthened HASYLAB's leadership in 1998 by establishing a board structure with two leadership positions in addition to the HASYLAB director. Since that year, HASYLAB's director has been invited to the meetings of both the Scientific Council and the Administrative Council, becoming more embedded in DESY's research planning.

The successful building, testing, and operation of the VUV-FEL strengthened the TESLA partnership considerably. However, TESLA experienced a severe blow shortly before the new free-electron laser became operational when Wiik died in a tragic accident in February 1999. ${ }^{64}$ TESLA had suddenly lost its key manager who had helped integrate the particle physics and synchrotron radiation communities at DESY. ${ }^{65}$ The Administrative Council appointed Albrecht Wagner (particle physicist), who had been DESY's Research Director since 1991, as the new chairman of DESY's Board of Directors. ${ }^{66}$

The Administrative Council wanted to ensure that the synchrotron radiation program was represented adequately in the Board of Directors. Following up on Board of Directors discussions that occurred before Wiik's death, the Administrative Council split DESY's research division into the particle physics and synchrotron radiation sections. They recruited Robert Klanner, formerly a leading scientist at HERA, as director of the particle physics section, and Jochen Schneider, who was also HASYLAB director, as director of the synchrotron radiation section. ${ }^{67}$ When Schneider assumed his new office in January 2000, the synchrotron radiation program was formally represented in the Board of Directors and on par with particle physics. ${ }^{68}$ The long "Babylonian exile" for synchrotron radiation research was over. ${ }^{69}$

In terms of the four theoretical categories of change processes introduced above, ${ }^{70}$ both the construction of the VUV-FEL and the creation of a new 
leadership position for synchrotron radiation on the Board of Directors can be interpreted as instances of layering, whereby the former represents an example of infrastructure layering and the latter an example of organizational layering. However, viewed from a long-term perspective, these two layering processes eventually led to the displacement of accelerator-based particle physics by photon science. This shows that the processes of change are not necessarily identical with the long-term results to which they lead. In other words, if accelerator-based particle physics had been continued at DESY, these developments would have simply added photon science without changing the overall direction of the laboratory. Yet, an important insight from historical institutionalism is that step-bystep processes are key in transforming existing institutions. Therefore, both the VUV-FEL and new leadership position on DESY's Board of Directors were important elements of the laboratory's gradual turn toward photon science.

\section{The Redeployment of PETRA for Photon Science (PETRA III)}

Since its dedication to synchrotron radiation, DORIS III had become increasingly popular among external users, not only because the number of experimental stations substantially increased after 1993 (from thirty-one to forty-two), but also because the available beam time more than doubled between 1992 and 1999 (from 2,354 to 5,497 annual hours). ${ }^{71}$ In addition, the HASYLAB team responded to user needs by constantly improving the technical performance of the machine and experimental stations. This provided reliable and effective conditions for conducting experiments, as evident in the high share of effective beam time used, which was typically more than ninety percent. ${ }^{72}$ The annual number of research organizations involved in synchrotron radiation research increased from 146 to 261 between 1992 and 1999. By the late 1990s, DORIS III had come to be regarded as a highly reliable synchrotron source, producing routine photon beams since 1994 and satisfying external users. ${ }^{73}$ In June 2001, EMBL decided to scale up its DESY outpost by twenty-five percent, employing nine new scientists and investing three million Deutschemarks (DM) in a new building. ${ }^{74}$

The conversion of PETRA into a dedicated synchrotron radiation source got underway in the late 1990s. PETRA was the flagship high energy physics machine at DESY in the 1970s, and since 1987 it had been used as an injector for HERA. Five years later, in November 1992, members of the Extended Scientific Council discussed the possibility of installing a test facility for synchrotron radiation and recommended an insertion device that would produce radiation with extremely short wavelengths (hard X-rays), almost at the limit of what was theoretically possible. ${ }^{75}$ This recommendation was approved by the Board of Directors, and construction of this new beamline started in $1994 .{ }^{76}$ It was housed in a new experimental hall built as part of a larger investment program for HASYLAB costing approximately eight million DM. ${ }^{77}$ In March 1995, the first beam of synchrotron radiation was observed at PETRA. This was perceived as a success, and 
in 1996 a second beamline was built to exploit lower wavelengths. ${ }^{78}$ However, the two beamlines were available for synchrotron radiation experiments only when injections for HERA were not needed, the function of PETRA as an injector for HERA was always prioritized. ${ }^{79}$ This was similar to the situation in the late $1970 \mathrm{~s}$ when DORIS served as injector for PETRA; thus, the use of PETRA for synchrotron radiation was severely restrained. ${ }^{80}$

The situation started to change when Schneider was offered the position of director general of the pan-European synchrotron radiation facility ESRF in August 1999. ${ }^{81}$ A few months after Wiik's death, it was clear to the Board of Directors that, if Schneider accepted the ESRF offer, the TESLA coalition would lose its second leader and be considerably weakened. This was not in the interest of the particle physicists who were eager to obtain funding for the linear collider. Therefore, the Board of Directors agreed in principle to dedicate PETRA to the synchrotron research program after the termination of HERA's operations. ${ }^{82}$ This sent a strong signal to the synchrotron radiation community, since the proposed conversion of PETRA had set high technical ambitions; it was going to make DESY the host of a state-of-the-art synchrotron radiation facility that would not only be competitive with, but even more attractive than, sources such as the ESRF, particularly in the hard X-ray region. ${ }^{83}$ Therefore, the decision clearly meant that the DESY Board of Directors staked out a future for the laboratory in which synchrotron radiation was one of its prime missions.

However, it took another two years until the plans for the conversion of the existing accelerator into PETRA III became more concrete. In September 2001, Schneider was offered the position of director of the Advanced Photon Source at Argonne National Laboratory. ${ }^{84}$ At that time, the TESLA project proposal was under review with the Science Council. Schneider inquired with the BMBF whether the conversion of PETRA into a dedicated synchrotron light source could be sped up. ${ }^{85}$ In late September 2001, the Board of Directors convened for a special meeting to discuss DESY's research strategy and approved January 2007 as the start of the "rededication of PETRA as an independent source of synchrotron light" and simultaneous termination of the HERA program. ${ }^{86}$ Following this decision, Schneider declined the job offer from Argonne. ${ }^{87}$

Although PETRA's conversion was conceded, DESY would not be able to fund it from its own budget. The conversion would be quite expensive, as oneeighth of the $2.3 \mathrm{~km}$-long ring had to be built anew and housed in a new experimental hall in order to host some eighteen new beamlines. ${ }^{88}$ Therefore, it was vitally important that the BMBF offered help sponsoring a working group tasked with preparing a technical design report for PETRA III. ${ }^{89}$ In February 2003, the BMBF decided to support PETRA's conversion with $€ 120$ million. ${ }^{90}$ Therefore, the research group was able to prepare its technical design report under the premise that funding would be made available. When the technical design report was issued in February 2004, ${ }^{91}$ DESY had already established the Photon Science Committee that would govern the selection of projects and allocate dedicated 
beam time for synchrotron radiation experiments. This new committee replaced the Research Council Synchrotron Radiation that had been in place since 1978. ${ }^{92}$

In February 2004, DESY submitted the technical design report for PETRA III, to which more than two hundred scientists from sixty-five organizations contributed, for international review. ${ }^{93}$ Following discussions inside and outside DESY, the Extended Scientific Council approved PETRA III in November 2004 and the Administrative Council approved it in December 2004. ${ }^{94}$ In May 2005, a "state contract" (Staatsvertrag) was signed for PETRA III. The federal government and the City of Hamburg, which shared responsibility for funding DESY, authorized the construction of PETRA III, the total cost of which was estimated at that time to be $€ 225$ million. ${ }^{95}$ Finally, when HERA was shut down in June 2007, the construction of PETRA III started. ${ }^{96}$ After two years of construction, in September 2009, PETRA III officially opened, and its operation as a user facility started in the spring of $2010 .^{97}$

In terms of the four theoretical categories of change processes introduced above, ${ }^{98}$ the redeployment of PETRA as a dedicated synchrotron radiation light source (PETRA III) represents a case of infrastructure conversion because it was built as a particle physics machine and later rebuilt and used for producing synchrotron radiation. The shutdown of HERA represents an instance of infrastructure dismantling, though the scientific activities associated with HERA have not been discontinued entirely. Data generated by this accelerator are still being processed by particle physicists at DESY. In addition, the basic technical infrastructure of HERA still sits in the six kilometers of tunnel under DESY and can, in principle, be restarted or rebuilt for new purposes, which would amount to infrastructure conversion in the long run. However, it is unlikely that HERA will be restarted for use in particle physics. Again, a long-term perspective indicates that PETRA's conversion and HERA's shutdown are elements in a process that eventually led to the displacement of accelerator-based particle physics by photon science.

\section{The Turn toward Photon Science}

The funding decision for the conversion of PETRA was part of a larger investment in photon science on behalf of the German federal government and DESY, particularly the European XFEL. As outlined above, Wiik, Schneider, and Materlik had forged a coalition; the TESLA project contained a linear collider for particle physics (TESLA-ILC) that would also power the free electron X-ray laser (TESLA-XFEL). After several years of testing and development, DESY submitted the TESLA technical design report to the Science Council for review. In March 2001, DESY presented the report at an international symposium in Hamburg attended by more than 1,100 participants from all over the world. ${ }^{99}$ The TESLA proposal was DESY's biggest project ever, much larger than HERA. The 
estimated total costs for the linear collider were $€ 3.4$ billion; the one billion DM cost of HERA paled in comparison. ${ }^{100}$

Given the scientific and technical complexity of the proposal, the Science Council's evaluation took more than a year. ${ }^{101}$ In July 2002, the council issued its preliminary review and asked DESY to submit a technical solution for the XFEL that would not require the TESLA-ILC, as well as a more detailed explanation of how the linear collider would be organized. In October 2002, DESY submitted two revised technical reports containing a separate and much smaller linear accelerator for the XFEL and a detailed scheme for the TESLA-ILC collaboration. ${ }^{102}$ The two revised proposals implied that TESLA-ILC could be decoupled, both technically and organizationally, from the XFEL. In November 2002, the Science Council approved the two revised proposals and recommended funding both. ${ }^{103}$

Decoupling TESLA-ILC from the XFEL was clearly against Wiik's intentions. However, it turned out to be an important step forward in the decision-making process. In February 2003, the BMBF presented its decision on the TESLA proposal at a press conference in Bonn. The BMBF decided to provide fifty percent of the European XFEL's estimated cost of $€ 684$ million (in year 2000 prices); the other half would have to be provided by European partners. In addition, the BMBF decided that it would provide no funding for the construction of TESLAILC. ${ }^{104}$ The BMBF's decision was a severe blow for the particle physics program at DESY. Albrecht Wagner and many DESY particle physicists, who had developed high expectations during the almost ten years of preparation for the TESLA proposal, were bitterly disappointed. ${ }^{105}$

Yet, the BMBF had packaged its decision in a way that offered the possibility for particle physicists to continue their linear collider plans. The BMBF had not cancelled TESLA-ILC, but formally approved it without providing funding. With this peculiar decision, the leadership of DESY could continue its efforts and submit a new proposal at any time in the future. Therefore, Albrecht Wagner argued in the first meeting of the Administrative Council after the February 2003 decision that the BMBF had not only made investments that would make DESY into "one of the leading laboratories for photon science worldwide," but that DESY should also "continue its research and development activities regarding the linear collider within an international collaboration." ${ }^{106}$ Importantly, though the XFEL was conceivable as a European collaborative project and later realized as such (see below), TESLA-ILC was large enough to warrant the entire global particle physics community joining forces. Therefore, in 2005 the Global Design Effort (GDE) was formed around the design and planning of the International Linear Collider (ILC), merging the achievements of the previous design and planning efforts of TESLA-ILC with the United States's Next Linear Collider (NLC) and other similar projects. ${ }^{107}$

Considerable controversy persisted within the BMBF about whether the DESY leadership should be allowed to continue its linear collider efforts, but eventually the BMBF conceded that the Board of Directors, in coordination with the new 
Helmholtz Association, was responsible for developing DESY's research strategy. ${ }^{108}$ In addition, following the Helmholtz reforms in 2001, the Chairman of the Board of Directors would have to streamline such plans in five-year research programs. Nevertheless, the BMBF wanted DESY's leadership to understand that with VUV-FEL, PETRA III, and the XFEL, DESY had three major infrastructural and scientific projects that demanded full dedication. Therefore, Hermann Schunck, the BMBF's representative at the Administrative Council, reminded DESY's leadership to focus on the projects that had been funded and give them priority over the linear collider. ${ }^{109}$

The first meeting of the International Steering Committee for the European XFEL was held in February 2004. One of the major tasks of this committee was to assemble support from European countries to co-fund the XFEL. ${ }^{110}$ In September 2004, the Federal Government, the City of Hamburg, and Schleswig-Holstein signed a "state contract" (Staatsvertrag) that formally authorized construction of the XFEL. The contract stated that the European XFEL would cost $€ 684$ million (at year 2000 prices), with fifty percent being the responsibility of the federal government, ten percent the responsibility of the City of Hamburg and Schleswig-Holstein, and forty percent the responsibility of European partners. ${ }^{111}$ In the three years that followed, a number of European partner countries joined the project, and in 2007 Russia decided to contribute 23.1 percent of the total construction costs, swiftly pushing the project toward the start of construction in January 2009. In September 2017, the European XFEL was officially opened. ${ }^{112}$

The XFEL decision concluded developments at DESY, signaling that its future would be accelerator-based photon science. By the end of the 2000s, all of DESY's large accelerator machines were dedicated to photon science. DESY operated DORIS III, a highly reliable and popular machine in the synchrotron radiation community, as indicated by its substantial oversubscription. ${ }^{113}$ DORIS III was shut down in 2012, after almost twenty years of service to the synchrotron radiation community. Furthermore, DESY upgraded the VUV-FEL into a full-scale user facility, providing a highly brilliant photon beam between 6 and $120 \mathrm{~nm}$. In August 2005, the VUV-FEL started operating as a user facility, and in 2006 received its new name, Free Electron Laser in Hamburg (FLASH). ${ }^{114}$ When PETRA III started operation in 2010, DESY operated three major photon science machines but no high energy physics machine (figure 3).

The shift toward photon science was also visible in the expansion of strategic research relationships with both the Max Planck Society and Hamburg University. In December 2003, DESY submitted its CFEL proposal to the Helmholtz Association. In 2004, the Helmholtz Senate recommended strengthening photon science at DESY, particularly the development and operation of free-electron lasers. ${ }^{115}$ Following this recommendation, the CFEL was founded in 2007 as a joint venture between DESY, the Max Planck Society, and Hamburg University after negotiations between the three partners. ${ }^{116}$ The BMBF supported the CFEL by 


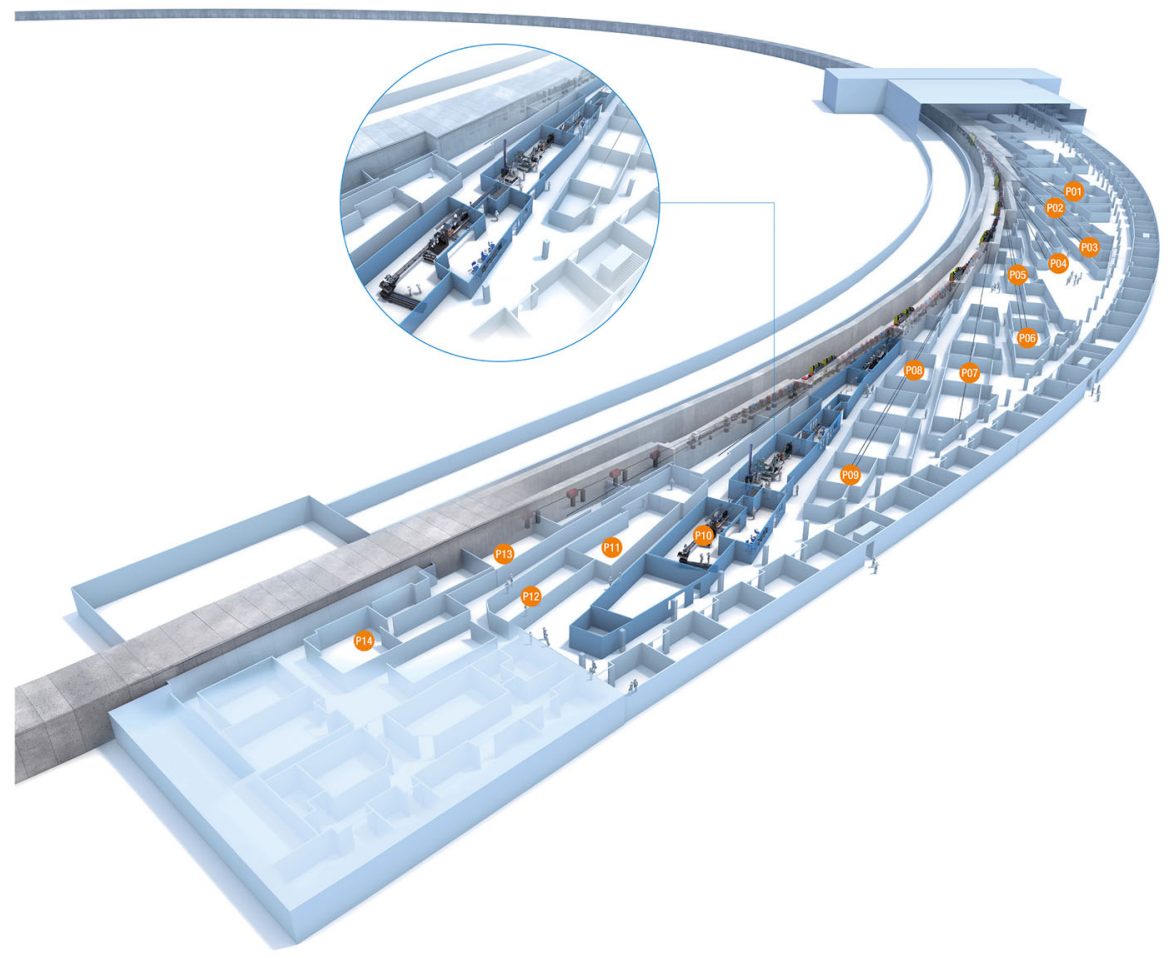

Fig. 3. Schematic layout of installations inside the experimental hall of PETRA III. Source: http://photon-science.desy.de/facilities/petra_iii/ (accessed March 20, 2017)

effectively doubling its synchrotron radiation research program from $€ 8.4$ million in 2006 to $€ 19.0$ million in 2007, and the City of Hamburg sponsored new laboratory and office buildings. In addition, the CFEL had five professorial staff positions for joint appointments with Hamburg University. ${ }^{117}$

In March 2009, the first photon scientist was appointed chairman of DESY's Board of Directors: Helmut Dosch. ${ }^{118}$ Prior to his appointment, Dosch had been director at the Max Planck Institute for Solid State Research in Stuttgart (19972009) and Professor of Material Sciences at the University of Wuppertal (19931997), where he had developed new methods using synchrotron radiation. ${ }^{119}$ Thus, in the same year that DESY celebrated its fiftieth anniversary, the laboratory's transformation from accelerator-based particle physics to multidisciplinary photon science manifested itself in a change in leadership.

In terms of the four theoretical categories of change processes introduced above, ${ }^{120}$ both construction of the European XFEL and founding of the CFEL can be interpreted as instances of layering; the former represents an example of 
infrastructure layering and the latter an example of organizational layering. Viewed from a long-term perspective, these two layering processes eventually provided the final momentum for the laboratory's transformation.

\section{Conclusions}

This article chronicles the most recent history of DESY's transformation from a laboratory founded as a resource for accelerator-based particle physics to a facility in which its main experimental program is multidisciplinary photon science. Today, DESY operates two photon science machines (FLASH and PETRA III) but no particle physics machine, and the next photon science machine on its site, the European XFEL, which opened very recently.

As shown here, DESY's turn toward photon science was made possible by a coalition between particle and accelerator physicists on the one hand, and photon scientists on the other hand. On the particle physics side, this coalition was meant to continue the accelerator-based particle physics program at DESY, but that did not happen because the Federal Research Ministry was not prepared to provide funding for yet another dedicated particle accelerator at DESY, a development that is in line with the more general trend of national programs in experimental particle physics being increasingly substituted by global coordinated programs; the LHC in Geneva is currently the strongest program worldwide. Yet, the accelerator physicists turned out to be key in overcoming skepticism and resistance among synchrotron radiation researchers. They helped redeploy, for photon science, scientific and technical capabilities that had been built up when accelerator-based particle physics was DESY's dominant scientific program.

Furthermore, institutional entrepreneurship unfolded in an increasingly supportive academic environment. Whereas, synchrotron radiation research at DESY yielded little resonance among professors at Hamburg University outside the physics department in the 1960 s and 1970 s, ${ }^{121}$ the fascinating perspectives of the European XFEL made all actors became aware that the expansion of multidisciplinary photon science would be severely limited without active support from professors at Hamburg University (and other research organizations on the DESY site, including the Max Planck Society and EMBL outposts), in fields as diverse as materials science, chemistry, and molecular biology. The foundation of the CFEL is important in this regard because it included joint faculty positions that established productive and durable institutional links between DESY and Hamburg University in photon science.

This article's theoretical framework draws on categories developed in the tradition of historical institutionalism that emphasizes gradual transformation, in contrast to disruptive discontinuities, such as political or social revolution, or pathdependent stabilities in which an existing institutional order is continuously reproduced. This framework is meant to direct greater attention to step-by-step developments that accumulate over time, deeply transforming existing structures. 
As shown throughout the article, DESY's most recent history provides several examples of infrastructure and science layering (VUV-FEL, XFEL), organizational layering (Photon Science Division, Research Director for Photon Science, CFEL), infrastructure conversion (PETRA III), and infrastructure dismantling (HERA). Taken together, these are elements in a long-term process that affects infrastructure, scientific activities, and formal organization alike. Thus, the overall conclusion from framing DESY's history in these terms is that we have witnessed a multistep and multidimensional process of abandoning accelerator-based high energy physics and the simultaneous build-up of multidisciplinary photon science within the same laboratory organization and overall political and financial framework. This shows the value of using theories of gradual, cumulative institutional change in analyses of the recent history of science.

Historical institutionalism invites comparisons. In this regard, one difference between DESY and its North American sibling SLAC is that the abandoning of accelerator-based high energy physics involved the shut-down of PEP-II, SLAC's then flagship particle physics machine, six months earlier than originally planned due to a funding cap in the Department of Energy's high energy physics program. In contrast, the shutdown of HERA, DESY's then flagship particle physics machine, occurred six months later than originally promised to the photon scientists who eagerly awaited this shutdown to eventually start the conversion of PETRA into a third-generation light source. The last months before the shutdowns of former flagship particle physics machines were emblematic in that SLAC turned to photon science more swiftly than DESY. Therefore, although similar processes of institutional change occurred in both laboratories, the speed of transformation differed depending on the particular organizational settings, collaborations between the actors involved, and the availability of resources.

In this regard, one conspicuous difference between DESY and SLAC is that the latter has redeployed its scientific and technical capabilities in accelerator-based particle physics not only in photon science, but also in astroparticle physics and cosmology. SLAC initiated an astrogravity research program in the mid-1990s, paving the way for a transition from accelerator-based particle physics to astroparticle physics and cosmology in the 2000s, when it founded the Kavli Institute for Particle Astrophysics and Cosmology, in cooperation with Stanford University. This additional redeployment involved a migration of several particle and accelerator physicists to the adjacent field and helped accomplish SLAC's "painful rebirth." ${ }^{122}$ Such a redeployment did not occur at DESY; thus, particle and accelerator physicists did not migrate into this growing field at DESY, which is one of the reasons why the laboratory's transformation took longer. ${ }^{123}$

The transformation chronicled in this article is part of a larger current of change in science and technology in the late twentieth century and after. This change complemented the dominance of nuclear and particle physics in national and international science budgets with a rise of life sciences and materials sciences and applications of similarly tremendous impact. Photon science took a lead position 
on the side of experimentation in these growing fields of research and development and became a new form of big science, generously funded by governments and with user communities expanding across both academia and industry. ${ }^{124}$

The change from nuclear and particle physics as the most prestigious and wellfunded areas of science in the Cold War era to a new, post-Cold War situation in which the life sciences, advanced materials sciences (including nanotechnology), and other scientific areas happened on several levels and in several different dimensions. Previous analyses have shown how the early exploration of synchrotron radiation at SLAC and DESY formed part of these grander transformations as important micro-level change processes contributing to the overall transformation as well as catalyzing it. ${ }^{125}$ In one sense, the present article is a sequel to the previous analyses, continuing the story of the same overall change process for seventeen more years. In another sense it is a separate analysis that shows the consequences of early work to use synchrotron radiation at DESY, namely what these early efforts produced in terms of broader, deeper, and more profound efforts to exploit accelerator technology for photon science.

This article has also focused its analyses on the changing relationship between synchrotron radiation/photon science activities gradually taking over larger shares of DESY's organizational and infrastructural capacities, and the high energy physics program, which was the original research mission of the laboratory. In the years preceding the starting point for the analysis of this article, the synchrotron radiation activities at DESY were mainly auxiliary and peripheral to the main mission of the laboratory, allowed to continue based on the consent of the particle and accelerator physicists, who were in charge of laboratory operations. As the article shows, the new scientific activities became central to the facility during the 1990s and 2000s. Thus, the formation of photon science at DESY occurred largely within pre-existing structures, where it underwent gradual growth in the shadow of a laboratory dedicated to experimental particle physics. A somewhat related observation has been made in innovation studies in which the initial processes of path-breaking technical innovations unfolded in the shadow of incumbent firms that shielded these innovations from socio-technical selection environments until they were robust enough to be competitive in their own right. ${ }^{126}$ Much in the early history of synchrotron radiation suggests that its development made it robust enough to take further steps and eventually become a big science in its own right, with DESY being part of a new organizational field in experimental science. ${ }^{127}$

\section{Acknowledegments}

The authors would like to express sincere thanks to Josefine Bäßler, Imke Fehsel, Manuel Cardona, Josef Feldhaus, Arlette Jappe, John Galayda, Stephan Haid, Lütfiye Kocyigit, Olaf Kühnholz, Christof Kunz, Frank Lehner, Erich Lohrmann, Gerhard Materlik, Richard Münch, Jochen Schneider, Hermann Schunck, Bernd Sonntag, Joachim Stöhr, Maja Stolper, and Albrecht Wagner. Special thanks also 
goes to Frank Lehner for his extremely valuable support in gaining access to the DESY archive and documentation, and for his general support for the project. This work was supported by the BMBF via grant 01UZ1001.

Open Access This article is distributed under the terms of the Creative Commons Attribution 4.0 International License (http://creativecommons.org/licenses/by/4.0/), which permits unrestricted use, distribution, and reproduction in any medium, provided you give appropriate credit to the original author(s) and the source, provide a link to the Creative Commons license, and indicate if changes were made.

\section{References}

${ }^{1}$ Olof Hallonsten, "The Parasites: Synchrotron Radiation at SLAC, 1972-1992," Historical Studies in the Natural Sciences 45 (2015), 217-72; Olof Hallonsten and Thomas Heinze, "Formation and Expansion of a New Organizational Field in Experimental Science," Science and Public Policy 42 (2015), 841-54. See also: Olof Hallonsten, Big Science Transformed: Science, Politics, and Organization in Europe and the United States (New York: Palgrave Macmillan, 2016).

${ }^{2}$ For a description of the technical and scientific basics of synchrotron radiation and free-electron laser, see Hallonsten, Big Science (ref. 1), 241-55.

${ }^{3}$ The following summary draws on Thomas Heinze, Olof Hallonsten, and Steffi Heinecke, "From Periphery to Center. Synchrotron Radiation at DESY, Part I: 1962-1977," Historical Studies in the Natural Sciences 45 (2015), 447-92.

${ }^{4}$ Hallonsten and Heinze, "Formation and Expansion" (ref. 1).

${ }^{5}$ The following summary draws on Thomas Heinze, Olof Hallonsten, and Steffi Heinecke, "From Periphery to Center. Synchrotron Radiation at DESY, Part II: 1977-1993," Historical Studies in the Natural Sciences 45 (2015), 513-48.

${ }^{6}$ Heinze et al., "From Periphery to Center 1962-1977" (ref. 3); "From Periphery to Center 19771993" (ref. 5); Erich Lohrmann and Paul Söding, Von schnellen Teilchen und hellem Licht: 50 Jahre Deutsches Elektronen-Synchrotron DESY, 2nd ed., (Weinheim: Wiley-VCH, 2013), 221-53.

${ }^{7}$ Catherine Westfall, "Surviving the Squeeze: National Laboratories in the 1970s and 1980s," Historical Studies in the Natural Sciences 38 (2008), 475-78; Florian Hars, "Wenn Forschung zu groß wird. Internationalisierung als Strategie nationaler Forschungsplanung am Beispiel der Hochenergiephysik," in Antworten auf die amerikanische Herausforderung. Forschung in der Bundesrepublik und der DDR in den "langen" siebziger Jahren, ed. Gerhard A. Ritter, Margit Szöllösi-Janze, and Helmuth Trischler (Frankfurt a. M.: Campus, 1999), 286-312.

${ }^{8}$ Hallonsten and Heinze, "Formation and Expansion" (ref. 1); Westfall, "Surviving the Squeeze" (ref. 7).

${ }^{9}$ Hallonsten, "The Parasites" (ref. 1); Olof Hallonsten and Thomas Heinze, "Institutional Persistence through Gradual Adaptation: Analysis of National Laboratories in the USA and Germany," Science and Public Policy 39 (2012), 450-63; Olof Hallonsten, "Growing Big Science in a Small Country: MAX-lab and the Swedish Research Policy System," Historical Studies in the Natural Sciences 41 (2011), 179-215; Catherine Westfall, "Surviving to Tell the Tale: Argonne's Intense Pulsed Neutron Source from an Ecosystem Perspective," Historical Studies in the Natural Sciences 40 (2010), 350-98; "Institutional Persistence and the Material Transformation of the US National Laboratories: The Curious Story of the Advent of the Advanced Photon Source," Science and Public Policy 39 (2012), 439-49; Robert P. Crease, "The National Synchrotron Light 
Source," 2 pts., "Part I: Bright Idea,"; "Part II: The Bakeout," Physics in Perspective 10 (2008), 438-67; 11 (2009), 14-45; Park Doing, Velvet Revolution at the Synchrotron: Biology, Physics, and Change in Science (Cambridge, MA: MIT Press, 2009).

${ }^{10}$ For a general introduction to historical institutionalism, see Orfeo Fioretos, Tulia G. Falleti, and Adam Sheingate, eds., The Oxford Handbook of Historical Institutionalism (New York: Oxford University Press, 2016); James Mahoney and Kathleen Thelen, "A Theory of Gradual Institutional Change," in Explaining Institutional Change: Ambiguity, Agency, and Power, ed. James Mahoney and Kathleen Thelen (Cambridge, UK: Cambridge University Press, 2010), 1-37; Wolfgang Streeck and Kathleen Thelen, "Introduction: Institutional Change in Advanced Political Economies," in Beyond Continuity: Institutional Change in Advanced Political Economies, ed. Wolfgang Streeck and Kathleen Thelen (New York: Oxford University Press, 2005), 1-39; Kathleen Thelen, "How Institutions Evolve: Insights from Comparative Historical Analysis," Comparative Historical Analysis in the Social Sciences, ed. James Mahoney and Dietrich Rueschemeyer (New York: Cambridge University Press, 2003), 208-40. For analyses using the theoretical framework of historical institutionalism in the context of science and technology, see Marek Kwiek, "Structural Changes in the Polish Higher Education System (1990-2010): A Synthetic View," European Journal of Higher Education 4 (2014), 266-80; Steffi Heinecke, "The Gradual Transformation of the Polish Public Science System," PLOS ONE 11 (2016), e0153260; Olof Hallonsten and Thomas Heinze, "From Particle Physics to Photon Science: Multidimensional and Multilevel Renewal at DESY and SLAC," Science and Public Policy 40 (2013), 591-603; Hallonsten and Heinze, "Institutional Persistence" (ref. 9); Hallonsten, Big Science (ref. 1), 13759.

${ }^{11}$ All archival material quoted in endnotes was retrieved from the DESY archive unless other archives are mentioned.

${ }^{12}$ The science budget in the Federal Republic of Germany doubled between 1962 and 1972; see Cathryn Carson, "Beyond Reconstruction: CERN's Second Generation Accelerator Program as an Indicator of Shifts in West German Science," in Physics and Politics: Research and Research Support in Twentieth Century Germany in Inter-national Perspective, ed. Helmuth Trischler and Mark Walker (Stuttgart: Steiner, 2000), 107-30.

${ }^{13}$ OECD, ed., Main Science and Technology Indicators (iLibrary, 2017), DOI: 10.1787/2304277; Main Economic Indicators (iLibrary, 2017), DOI: 10.1787/22195009. Calculations based on the following variables: GERD and GDP at constant prices and purchasing power parities (2010 million \$US or $€$ ), government-financed GERD as a percentage of GDP, government budget appropriations or outlays in research and development at constant prices, and purchasing power parities (2010 million \$US or $€$ ).

${ }^{14}$ Ibid.

15 Ibid.

${ }^{16}$ National Science Foundation, accessed August 12, 2017, https://dellweb.bfa.nsf.gov/ NSFFundingbyAccountConstantDollars.pdf; Department of Energy, accessed August 12, 2017, https://science.energy.gov/bes/about/bes-budget/.

${ }^{17}$ CERN Annual Reports, 2000-2005, accessed August 13, 2017, https://cds.cern.ch/collection/ CERN\%20Annual\%20Reports.

${ }^{18}$ Thomas Heinze and Stefan Kuhlmann, "Across Institutional Boundaries? Research Collaboration in German Public Sector Nanoscience," Research Policy 37 (2008), 888-99; Thomas Heinze and Natalie Arnold, "Governanceregimes im Wandel. Eine Analyse des außeruniversitären, staatlich finanzierten Forschungssektors in Deutschland," Kölner Zeitschrift für Soziologie und Sozialpsychologie 60 (2008), 686-722. 
${ }^{19}$ Olaf Bartz, Der Wissenschaftsrat. Entwicklungslinien der Wissenschaftspolitik in der Bundesrepublik Deutschland 1957-2007 (Stuttgart: Franz Steiner, 2007), 204-10; Deutscher Bundestag, ed., Politische Konsequenzen aus der Evaluierung der Fraunhofer-Gesellschaft (FhG), Max-Planck-Gesellschaft (MPG) und Deutschen Forschungsgemeinschaft (DFG), Bundestagsdrucksache BT14-1764 (Berlin, 1999), 1.

${ }^{20}$ Heinze and Arnold, "Governanceregimes im Wandel" (ref. 18), 692; Olof Hallonsten and Thomas Heinze, "Preservation of the Laboratory Is Not a Mission: Gradual Organizational Renewal in National Laboratories in Germany and the USA," in Innovation in Science and Organizational Renewal: Historical and Sociological Perspectives, ed. Thomas Heinze and Richard Münch (New York: Palgrave Macmillan, 2016), 122-25.

${ }^{21}$ Fraunhofer-Gesellschaft, ed., Systemevaluierung der Fraunhofer-Gesellschaft. Bericht der Evaluierungskommission (München: FhG, 1998); Internationale Kommission, ed., Forschungsförderung in Deutschland. Bericht der internationalen Kommission zur Systemevaluation der Deutschen Forschungsgemeinschaft und der Max-Planck-Gesellschaft (Hannover: Volkswagen-Stiftung, 1999), 17-20, 37-38, 41-43.

${ }^{22}$ Wissenschaftsrat, ed., Systemevaluation der Blauen Liste, Drucksache 4703/00 (Bonn: WR, 2000), 8, 34-37, 49-50; Wissenschaftsrat, ed. Systemevaluation der HGF, Drucksache 4755/01 (Bonn: WR, 2001), 61-68.

${ }^{23}$ Wissenschaftsrat, Systemevaluation HGF (ref. 22), 64-65.

${ }^{24}$ Heinze and Arnold, "Governanceregimes im Wandel” (ref. 18).

${ }^{25}$ Wissenschaftsrat, Systemevaluation HGF (ref. 22), 84-107.

${ }^{26}$ Thomas Groß and Natalie Arnold, Regelungsstrukturen der außeruniversitären Forschung (Baden-Baden: Nomos, 2007), 97-133.

${ }^{27}$ Deutscher Bundestag, ed., Planungen der Bundesregierung zur Strukturveränderung der Helmholtz-Gemeinschaft Deutscher Forschungszentren, Bundestagsdrucksache BT14-3279 (Berlin, 2000), 7.

${ }^{28}$ Deutscher Bundestag, ed., Forschungsfreiheit sichern - keine politische Steuerung der Helmholtz-Zentren, Bundestagsdrucksache BT14-5249 (Berlin, 2001), 1-3; Deutscher Bundestag, ed., Programmorientierte Förderung der Helmholtz-Zentren. Antwort der Bundesregierung, Bundestagsdrucksache BT14-6156 (Berlin, 2001), 1.

${ }^{29}$ Thomas Heinze, "Zentralisierung und Hierarchisierung. Der Wandel des Qualitätsmanagements in der außeruniversitären Forschung," Wissenschaftsmanagement 13 (2010), 35-39; Sabine Helling-Moegen, Forschen nach Programm. Die programmorientierte Förderung in der Helmholtz-Gemeinschaft: Anatomie einer Reform (Marburg: Tectum, 2009), 175-209.

${ }^{30}$ Heinze et al., "From Periphery to Center 1977-1993" (ref. 3), 531-32.

${ }^{31}$ Lohrmann and Söding, "Von schnellen Teilchen" (ref. 6), 115.

${ }^{32}$ DESY, ed., Wissenschaftlicher Jahresbericht 1991 (Hamburg: DESY, 1991), 164.

${ }^{33}$ Lohrmann and Söding, "Von schnellen Teilchen" (ref. 6), 300.

${ }^{34}$ DESY, ed., Wissenschaftlicher Jahresbericht 1992 (Hamburg: DESY, 1992), 237-43.

35 J. R. Schneider, interviews with Thomas Heinze, April 25, 2012, and May 7, 2014, DESY Hamburg; H. Schunck, interview with Thomas Heinze, October 10, 2012, Bonn.

${ }^{36}$ DESY, ed., Wissenschaftlicher Jahresbericht 1994 (Hamburg: DESY, 1994), 214.

${ }^{37}$ Max Cornacchia and Herman Winick, eds., Proceedings of the Workshop "Fourth Generation Light Sources,” Rep. 92/02 (Menlo Park: SSRL/SLAC, 1992).

${ }^{38}$ Claudio Pellegrini, "A 4 to $0.1 \mathrm{~nm}$ FEL Based on the SLAC Linac," in Cornacchia and Winick, Proceedings (ref. 37), 364-75. 
${ }^{39}$ Herman Winick and Arthur Bienenstock, Proposal to the Department of Energy for $R \& D$ Studies Relating to the Construction of a 2.3-4.4 nm Linac Coherent Light Source (LCLS) Based on the SLAC Linac (Menlo Park: SSRL, 1992), SLAC Archives, 2000-024, Box 3, Folder 2.

${ }^{40}$ Ilan Ben-Zvi et al., "Technical Review Report, Linac Coherent Light Source, SLAC, November 21-22, 1992," SLAC Archives, 2000-024, Box 3; Herman Winick, "The Genesis of the LCLS," presentation at the ICFA Workshop on Future Light Sources, Newport News, VA, March 8, 2012, accessed March 20, 2017, https://www.jlab.org/conferences/FLS2012/.

${ }^{41}$ John Arthur, Gerd Materlik, and Herman Winick, Workshop on Scientific Applications of Coherent X-Rays, SLAC Report 437 (Menlo Park: SLAC, 1994).

${ }^{42}$ B. Sonntag, interview with Thomas Heinze, October 11, 2012, University of Wuppertal.

${ }^{43}$ DESY, Wissenschaftlicher Jahresbericht 1995 (Hamburg: DESY, 1995), 10.

${ }^{44}$ Claudio Pellegrini, "The History of X-ray Free Electron Lasers," The European Physical Journal H 37 (2012), 686.

${ }^{45}$ Sonntag, interview with Heinze (ref. 41); Schneider, interview with Heinze (ref. 34); J. Stöhr, interview with Thomas Heinze and Olof Hallonsten, March 26, 2013, SLAC.

${ }^{46}$ Winick, "Genesis of the LCLS" (ref. 40), 28.

${ }^{47}$ Stöhr, interview with Heinze and Hallonsten (ref. 45).

${ }^{48}$ Gerd Materlik, interview with Thomas Heinze, April 29, 2014, DESY Hamburg.

${ }^{49}$ DESY, A VUV Free Electron Laser at the TESLA Test Facility at DESY, Conceptual Design Report, TESLA FEL 95-03 (Hamburg: DESY, 1995); DESY, Wirtschaftsplan DESY 1996, 89; HASYLAB, Jahresbericht HASYLAB, 1995, 4.

${ }^{50}$ DESY, Wissenschaftlicher Jahresbericht 1997 (Hamburg: DESY, 1997), 36, 245-50; Wissenschaftlicher Jahresbericht 1998 (Hamburg: DESY, 1998), 219-25.

${ }^{51}$ DESY, Wissenschaftlicher Jahresbericht 1999 (Hamburg: DESY, 1999), 225-29.

${ }^{52}$ DESY, Wissenschaftlicher Jahresbericht 2000 (Hamburg: DESY, 2000), 5, 8, 117, 245-248.

${ }^{53}$ DESY, Wissenschaftlicher Jahresbericht 2001 (Hamburg: DESY, 2001), 234.

${ }^{54}$ Pellegrini, "X-ray Free Electron Lasers" (ref. 44), 691-93.

${ }^{55}$ Stephen R. Leone et al., "Report of the Basic Energy Sciences Advisory Committee Panel on Novel Coherent Light Sources,” January 18-22, 1999, 28, accessed March 20, 2017, https://science. energy.gov/ /media/bes/besac/pdf/Ncls_rep.pdf.

${ }^{56}$ SLAC, Linac Coherent Light Source (LCLS), Conceptual Design Report, SLAC-R-593 (Menlo Park: SLAC, 2002).

${ }^{57}$ Daniel R. Lehman et al., Close-Out Report on the Department of Energy's Review Committee for the Technical, Cost, Schedule, and Management Review of the Linac Coherent Light Source (LCLS) Project (Washington: Department of Energy, 2002).

${ }^{58}$ J. Galayda, interview with Olof Hallonsten, November 12, 2007, SLAC.

${ }^{59}$ DESY, Conceptual Design Reports of a $500 \mathrm{GeV} e^{+} e^{-}$Linear Collider with an Integrated X-Ray Laser Facility, Report 97-048 (Hamburg: DESY, 1997).

${ }^{60}$ DESY, Wissenschaftlicher Jahresbericht 1996 (Hamburg: DESY, 1996), 153, 204-10.

${ }^{61}$ DESY, Wissenschaftlicher Jahresbericht 1997 (ref. 50), 289.

${ }^{62}$ SLAC, Institutional Plan FY 1998-2002 (Menlo Park: SLAC, 1998), SLAC Archives 2008-037, Box 2, Folder 45, v.

${ }^{63}$ SLAC, Institutional Plan FY 2001-2006 (Menlo Park: SLAC, 2001), SLAC Archives 2009-069, Box 2, Folder 18, v. 
${ }^{64}$ DESY, ed., Jahresbericht (Hamburg: DESY, 1999), 7.

${ }^{65}$ Sonntag, interview with Heinze (ref. 44); Materlik, interview with Heinze (ref. 48).

${ }^{66}$ Schunck, interview with Heinze (ref. 35); Verwaltungsrat, "Niederschrift über die 90. Sitzung des Verwaltungsrats am 6.7.1999”; DESY, Press Release Archive, July 9, 1999, accessed March 20, 2017, http://www.desy.de/aktuelles/news/archiv_vor_2010/1999/desy_0807/index_ger.html.

${ }^{67}$ Verwaltungsrat, "Niederschrift" (ref. 66); Verwaltungsrat, "Niederschrift über die 91. Sitzung des Verwaltungsrats am 9.12.1999"; Thomas Heinze, interviews with A. Wagner, October 31, 2012, and January 28, 2014, DESY Hamburg; DESY Press Release Archive, December 13, 1999, accessed March 20, 2017, http://www.desy.de/aktuelles/news/archiv_vor_2010/1999/desy_1312/ index_ger.html.

${ }^{68}$ DESY, Wissenschaftlicher Jahresbericht 2000 (ref. 52), 12.

${ }^{69}$ Schunck, interview with Heinze (ref. 35).

${ }^{70}$ Hallonsten and Heinze, "Institutional Persistence" (ref. 9); Fioretos et al., Oxford Handbook (ref. 10); Mahoney and Thelen, "A Theory" (ref. 10); Streeck and Thelen, "Introduction: Institutional Change" (ref. 10); Thelen, "How Institutions Evolve" (ref. 10); Hallonsten and Heinze, "From Particle Physics" (ref. 10).

${ }^{71}$ See Table 1. Effective beam time in 1993: 96\%, 1994: 90\%, 1995: 80\%, 1996: 90\%, 1997: 91\%, 1998: 91\%, 1999: 93\%.

${ }^{72}$ DESY, Wissenschaftlicher Jahresbericht 1993 (Hamburg: DESY, 1993), 187; DESY, Wissenschaftlicher Jahresbericht 1994 (ref. 36), 36; DESY, Wissenschaftlicher Jahresbericht 1995 (ref. 42), 187; DESY, Wissenschaftlicher Jahresbericht 1996 (ref. 60), 109; DESY, Wissenschaftlicher Jahresbericht 1997 (ref. 50), 211; DESY, Wissenschaftlicher Jahresbericht 1998 (Hamburg: DESY, 1998), 181; DESY, Wissenschaftlicher Jahresbericht 1999 (ref. 51), 175.

${ }^{73}$ See Table 1.

${ }^{74}$ Verwaltungsrat, "Niederschrift über die 94. Sitzung des Verwaltungsrats, 18-19.6. 2001.”

${ }^{75}$ Extended Scientific Council, "Minutes of the 33rd Meeting of the Extended Scientific Council of DESY on 26 Nov 1992." The minutes were written in English due to the presence of non-Germanspeaking members of this council.

${ }^{76}$ DESY, Wissenschaftlicher Jahresbericht 1993 (Hamburg: DESY, 1993), 33; DESY, Wissenschaftlicher Jahresbericht 1994 (ref. 36), 37, 173.

${ }^{77}$ DESY, Wirtschaftsplan (Hamburg: DESY, 1995), Table 3.

${ }^{78}$ DESY, Wissenschaftlicher Jahresbericht 1995 (ref. 43), 116, 118.

${ }^{79}$ Wissenschaftlicher Rat, "Niederschrift der 103. Sitzung des Wissenschaftlichen Rates am 15.3. 1994."

${ }^{80}$ Heinze et al., "From Periphery to Center 1962-1977" (ref. 3), 481-82.

${ }^{81}$ Schneider, interviews with Heinze (ref. 35).

${ }^{82}$ Direktorium, "Niederschrift der Direktoriumssitzung am 26.8. 1999."

${ }^{83}$ DESY, Wissenschaftlicher Jahresbericht 1999 (ref. 51), 103-4.

${ }^{84}$ Schneider, interviews with Heinze (ref. 35).

${ }^{85}$ Ibid.

${ }^{86}$ Direktorium, "Niederschrift der Klausurberatung des Direktoriums am 27.9. 2001"; DESY,

"Wissenschaftlicher Jahresbericht 2001" (ref. 53), 108, 197. 
${ }^{87}$ Direktorium, “Niederschrift der Direktoriumssitzung am 11.10. 2001." Schneider's decision was also influenced by his strong believe that there was a good chance that the XFEL part of the TESLA project might be realized (ref. 35).

${ }^{88}$ DESY, PETRA III Technical Design Report (Hamburg: DESY, 2004), 10-13.

${ }^{89}$ DESY, Wissenschaftlicher Jahresbericht 2002 (Hamburg: DESY, 2002), 8, 194, 195.

${ }^{90}$ DESY, Wissenschaftlicher Jahresbericht 2003 (Hamburg: DESY, 2003), 124.

${ }^{91}$ DESY, Wissenschaftlicher Jahresbericht 2004 (Hamburg: DESY, 2004), 134.

${ }^{92}$ DESY, Wissenschaftlicher Jahresbericht 2004 (ref. 90), 15.

${ }^{93}$ Ibid., 134.

${ }^{94}$ Ibid., 197.

${ }^{95}$ DESY, Wissenschaftlicher Jahresbericht 2005 (Hamburg: DESY, 2005), 17.

${ }^{96}$ DESY, Wissenschaftlicher Jahresbericht 2007 (Hamburg: DESY, 2007), 238, 254.

${ }^{97}$ DESY, Wissenschaftlicher Jahresbericht 2003 (Hamburg: DESY, 2003), 7; DESY, Wissenschaftlicher Jahresbericht 2010 (Hamburg: DESY, 2010), 28.

${ }^{98}$ Hallonsten and Heinze, "Institutional Persistence" (ref. 9); Fioretos et al., Oxford Handbook (ref. 10); Mahoney and Thelen, "A Theory" (ref. 10); Streeck and Thelen, "Introduction: Institutional Change" (ref. 10); Thelen, "How Institutions Evolve" (ref. 10); Hallonsten and Heinze, "From Particle Physics" (ref. 10).

${ }^{99}$ Verwaltungsrat, "Niederschrift 2001" (ref. 74).

${ }^{100}$ DESY, Wissenschaftlicher Jahresbericht 2001 (ref. 53), 7, 32, 188.

${ }^{101}$ Wissenschaftsrat, ed., "Stellungnahme zu neun Großgeräten der naturwissenschaftlichen Grundlagenforschung und zur Weiterentwicklung der Investitionsplanung von Großgeräten,” Drucksache 5363/02 (Bonn: WR, 2002).

${ }^{102}$ Verwaltungsrat, "Niederschrift über die 97. Sitzung des Verwaltungsrates, 4.-5.12. 2002"; DESY, "Wissenschaftlicher Jahresbericht 2002" (ref. 89), 181-82.

${ }^{103}$ Wissenschaftsrat, "Stellungnahme" (ref. 101), 36-42; DESY, "Wissenschaftlicher Jahresbericht 2002" (ref. 89), 7-8.

${ }^{104}$ DESY, “Wissenschaftlicher Jahresbericht 2003” (ref. 91), 127.

${ }^{105}$ Heinze, interviews with Wagner (ref. 67), Schunck (ref. 35), and Schneider (ref. 35).

${ }^{106}$ Verwaltungsrat, “Niederschrift über die 98. Sitzung des Verwaltungsrates, 12.-13.6. 2003.”

107 “International Linear Collider Reference Design Report," ILC Global Design Effort and World Wide Study, August 2007, 1-7.

${ }^{108}$ Heinze, interview with Schunck (ref. 35).

109 Verwaltungsrat, "Niederschrift" (ref. 106).

${ }^{110}$ DESY, Wissenschaftlicher Jahresbericht 2004 (ref. 90), 8.

111 Ibid., 199.

${ }^{112}$ DESY, press release online archive, accessed September 14, 2017, http://www.desy.de/news/news_ search/index_eng.html?openDirectAnchor=1267\&two_columns=1; see also: Olof Hallonsten, "The Politics of European Collaboration in Big Science," in The Global Politics of Science and Technology, vol. 2, ed. Maximilian Mayer, Mariana Carpes, and Ruth Knoblich (Heidelberg: Springer, 2014), 40.

${ }^{113}$ DESY, Wissenschaftlicher Jahresbericht 2006 (Hamburg: DESY, 2006), 9.

${ }^{114}$ DESY, Wissenschaftlicher Jahresbericht 2004 (ref. 90), 8, 125, 130; DESY, Wissenschaftlicher Jahresbericht 2005 (ref. 95), 8. 
115 DESY, Wissenschaftlicher Jahresbericht 2005 (ref. 95), 16.

116 DESY, Wissenschaftlicher Jahresbericht 2006 (ref. 113), 17; DESY, Wissenschaftlicher Jahresbericht 2007 (ref. 96), 9, 21.

117 Deutscher Bundestag, ed., "Unterrichtung durch die Bundesregierung: Bundesbericht Forschung und Innovation 2008," Bundesdrucksache BT16-9260 (Berlin: Bundestag, 2008), 340.

118 DESY, press release online archive, accessed March 20, 2017, http://www.desy.de/aktuelles/ news/archiv_vor_2010/2009/dosch_desy_direktor/index_ger.html.

119 DESY, official website, accessed March 20, 2017, http://www.desy.de/sites2009/site_www-desy/ content/e410/e56047/e56067/e66828/infoboxContent66829/CVDoschHomepageenglisch_eng.pdf.

${ }^{120}$ Hallonsten and Heinze, "Institutional Persistence" (ref. 9); Fioretos et al., Oxford Handbook (ref. 10); Mahoney and Thelen, "A Theory" (ref. 10); Streeck and Thelen, "Introduction: Institutional Change" (ref. 10); Thelen, "How Institutions Evolve" (ref. 10); Hallonsten and Heinze, "From Particle Physics" (ref. 10).

${ }^{121}$ Heinze et al., "From Periphery to Center" (ref. 3), 462-63.

122 Adrain Cho, "For a Famous Physics Laboratory, A Quick and Painful Rebirth," Science 326 (2009), 221-23.

${ }^{123}$ Following the German reunification, the former astrophysics institute of the East German Science Academy in Zeuthen (near Berlin) was incorporated into the DESY organization. However, unlike the situation at SLAC, DESY-Zeuthen did not absorb high energy physicists into its research program once DESY-Hamburg shifted increasingly to photon science.

${ }^{124}$ Hallonsten, Big Science (ref. 1); Robert Crease and Catherine Westfall, "The New Big Science," Physics Today 69, no. 5 (2016), 30-36.

125 Hallonsten, "The Parasites" (ref. 1); Heinze et al., "From Periphery to Center 1962-1977" (ref. 3); Heinze et al., "From Periphery to Center 1977-1993" (ref. 3).

126 Johan W. Schot, Remco Hoogma, Boelie Elzen, "Strategies for Shifting Technological Systems: The Case of the Automobile System,” Futures 26 (1994), 1060-76; René Kemp, Johan W. Schot, Remco Hoogma, "Regime Shifts to Sustainability through Processes of Niche Formation: The Approach of Strategic Niche Management," Technology Analysis \& Strategic Management 10 (1998), 175-95.

${ }^{127}$ Hallonsten and Heinze, "Formation and Expansion" (ref. 1).

Interdisciplinary Center for Science and Technology Studies, University of Wuppertal

Gaußstrasse 20

42119 Wuppertal, Germany

e-mail: theinze@uni-wuppertal.de

Lund University School of Economics and Management

P.O. Box 7080, 22007 Lund, Sweden

e-mail: olof.hallonsten@fek.lu.se

Institute of Sociology, University of Wuppertal

Gaußstrasse 20

42119 Wuppertal, Germany

e-mail: sheinecke@uni-wuppertal.de 